This is the submitted version of the following article:

Maldonado J., González-Guerrero A.B., Domínguez C., Lechuga L.M.. Label-free bimodal waveguide immunosensor for rapid diagnosis of bacterial infections in cirrhotic patients. Biosensors and Bioelectronics, (2016). 85. : 310 - . 10.1016/j.bios.2016.04.095,

which has been published in final form at https://dx.doi.org/10.1016/j.bios.2016.04.095 (c) https://dx.doi.org/10.1016/j.bios.2016.04.095. This manuscript version is made available under the CC-BY-NC-ND 4.0 license http://creativecommons.org/licenses/by-nc-nd/4.0/ 


\title{
Label-free bimodal waveguide immunosensor for rapid diagnosis of bacterial infections in cirrhotic patients
}

Jesús Maldonadoa, Ana Belén González-Guerrero ${ }^{\mathrm{a}}$, Carlos Domínguez ${ }^{\mathrm{b}}$ and Laura M. Lechuga $^{\mathrm{a}, *}$

a Nanobiosensors and Bioanalytical Applications Group. Catalan Institute of Nanoscience and Nanotechnology (ICN2). CSIC and CIBER-BBN, Campus UAB, Ed-ICN2, 08193 Bellaterra, Barcelona, Spain.

${ }^{\mathrm{b}}$ Microelectronic Institute of Barcelona (IMB-CNM), CSIC, Campus UAB, 08193 Bellaterra, Barcelona, Spain.

*Corresponding author.

E-mail address: laura.lechuga@ cin2.es (Laura M. Lechuga)

\begin{abstract}
Spontaneous bacterial peritonitis is an acute bacterial infection of ascitic fluid; it has a high incidence in cirrhotic patients and it is associated with high mortality. In such a situation, early diagnosis and treatment is crucial for the survival of the patient. However, bacterial analysis in ascitic fluid is currently based on culture methods, which are time-consuming and laborious. We report here the application of a photonic interferometer biosensor based on a bimodal waveguide (BiMW) for the rapid and label-free detection of bacteria directly in ascitic fluid. The device consists of a straight waveguide in which two modes of the same polarization interfere while interacting with the external medium through their evanescent fields. A bimolecular event occurring on the sensor area of the device (e.g. capturing bacteria) will differently affect each light mode, inducing a variation in the phase of the light exiting at the output of the waveguide. In this work, we demonstrate the quantitative detection of Bacillus cereus in buffer medium and Escherichia coli in undiluted ascitic fluid from cirrhotic patients. In
\end{abstract}


the case of Bacillus cereus detection, the device was able to detect bacteria in 15 min reaching limit of detections of $12 \mathrm{cfu} \cdot \mathrm{mL}^{-1}$ (cfu: colony forming unit) and in the case of Escherichia coli detection, the analysis time was 25 min obtaining a detection limit of 4 $\mathrm{cfu} \cdot \mathrm{mL}^{-1}$. Based on the results obtained, we consider that the BiMW biosensor is positioned as a promising new clinical tool for user-friendly, cost-effective and realtime microbiological analysis.

Keywords: Bimodal waveguide biosensor, label-free immunoassay, Bacillus cereus, Escherichia coli, ascitic fluid.

\section{Introduction}

A large proportion of cirrhotic patients has ascites (Fernández and Gustot 2012), i.e. an accumulation of fluid in the abdominal cavity. The infection of this ascitic fluid, called spontaneous bacterial peritonitis (SBP), is a common complication in these patients and the most frequent bacterial infection in cirrhosis. If this is not promptly diagnosed, the patient may develop multiorgan failure and severe infection in the blood. However, conventional clinical analysis of bacterial infections in ascites is based on cultures that are accurate methods but time-consuming and require highly skilled personnel. Several non-culture methods based on molecular techniques such as real-time PCR and microarrays have been developed. Although these techniques allow highly sensitive identification of bacteria and are faster than culture, they involve sample amplification and the use of fluorescence labels for the detection. These additional processes significantly increase the cost of the analysis and, as a consequence, molecular techniques cannot be extended to all pathogen detections performed in hospitals. Hence, culture methods still remain the gold standard for identifying bacteria in infected cirrhotic patients.

So far, different label-free biosensing technologies have demonstrated their potential for fast and real-time microorganism diagnosis such the detection of Bacillus anthracis spores using a piezoelectric microcantilever sensor (McGovern et al. 2008), the detection of Escherichia coli using nonfaradic electrochemical impedance spectroscopy (Maalouf et al. 2007) and the detection of Salmonella Typhimurium by an automated quartz crystal microbalance (Salam et al. 2013). However, optical biosensors have 
attracted increasing attention in microbiological testing, since in addition to the labelfree detection, they can offer a highly sensitive analysis, miniaturization and costeffective production. The sensing principle that these devices employ is based on evanescent field detection; i.e. part of the light confined in a waveguide material can travel outside interacting with the external medium. Changes in the external refractive index affect (by its evanescent field) some property of the confined light (phase, intensity, wavelength...) that can be measured. Several evanescent wave biosensors have demonstrated their suitability for the label-free testing of bacteria. The detection of $10^{6} \mathrm{cfu} \cdot \mathrm{mL}^{-1}$ (cfu: colony forming unit) of Escherichia coli in buffer medium has been attained by an immunoassay using a surface plasmon resonance (SPR) biosensor. By implementing a sandwich assay, the SPR biosensor detected Escherichia coli concentrations 3 orders of magnitude lower than by a direct assay (Subramanian et al. 2006). Recently, the detection of Escherichia coli at a concentration of $50 \mathrm{cfu} \cdot \mathrm{mL}^{-1}$ has been achieved by combining spectroscopy of grating-coupled long-range surface plasmons (LRSPs) with a magnetic nanoparticle (MNP) assay (Wang et al. 2012). SPR biosensors employing bacteriophages probes, instead of antibodies as bioreceptors, can achieve limits of detections of $10^{2}-10^{3} \mathrm{cfu} \cdot \mathrm{mL}^{-1}$ in buffer medium (Arya et al. 2011; Balasubramanian et al. 2007). Fiber optic biosensors have been also reported for detection of Salmonella, obtaining detection limits of $10^{3} \mathrm{cfu} \cdot \mathrm{mL}^{-1}$ in buffer medium and $10^{4} \mathrm{cfu} \cdot \mathrm{mL}^{-1}$ in real food samples (Valadez et al. 2009). In a following work, the same sensor was multiplexed to detect simultaneously three pathogens (Listeria moncytogenes, Escherichia coli and Salmonella enterica) at concentrations of $10^{3}$ $\mathrm{cfu} \cdot \mathrm{mL}^{-1}$ by later reaction with labeled antibodies (Ohk and Bhunia 2013). By employing a complete label-free scheme, concentrations as low as $5 \times 10^{4} \mathrm{cfu} \cdot \mathrm{mL}^{-1}$ of Escherichia coli were detected using transmitted laser intensity by capturing the bacteria on a glass modified with antibodies (Acharya et al. 2006) and Bacillus subtilis was detected at a concentration of $8 \times 10^{4} \mathrm{cfu} \cdot \mathrm{mL}^{-1}$ employing a leaky waveguide sensor devices (LWD) (Zourob et al. 2005). Although it has been demonstrated that optical biosensors provide rapid identification of bacteria, pre-enrichment of the sample or amplification of the signal are mandatory to achieve detections at relevant physiological levels (from $10^{1}$ to $10^{4} \mathrm{cfu} \cdot \mathrm{mL}^{-1}$ ). Therefore, there is an urgent unmet medical need for new label-free detection systems able to detect low bacteria concentrations in complex samples without the requirement of previous pretreatments. 
With this in mind, we developed a highly sensitive immunosensor based on the Bimodal Waveguide (BiMW) device for the direct and label-free identification of bacteria in ascitic fluid of cirrhotic patients. In this sensor, light is confined in a silicon nitride $\left(\mathrm{Si}_{3} \mathrm{~N}_{4}\right)$ waveguide covered with silicon oxide $\left(\mathrm{SiO}_{2}\right)$ as cladding (see Fig. 1a). Initially, light is coupled in a single mode waveguide propagating the fundamental mode. After some distance, it is coupled in another waveguide supporting two-modes; the fundamental and the first mode. Then, both modes interfere and propagate until they exit the output of the waveguide. By opening the cladding at the bimodal part, the waveguide is exposed to the external medium, the sensor area of the device, where the bioreceptors (antibodies) are immobilized by covalent coupling. When the surface refractive index changes (e.g. by capturing a bacterium), both modes are differently affected through their evanescent fields which induces a phase variation in the light output. It is relevant to stress that the waveguide used in our study had highly reduced dimensions (see Fig. 1b); it consisted of a rib $4 \mu \mathrm{m}$ wide and $1.5 \mathrm{~nm}$ high. The chips $(30$ $\mathrm{mm}$ length and $10 \mathrm{~mm}$ width as shown in Fig. 1c) were fabricated using silicon standard microfabrication techniques which significantly reduce the cost per sensor. Another key point in our design is that the output signal is not sensitive to fluctuations in the coupling efficiency; it is not affected by either the thermal expansion of the mechanical holder or the fluctuations in the input light. It is achieved by normalizing the signal (S), proportional to the phase variations $(\Delta \varphi(\mathrm{t}))$, with the total intensity $\left(\mathrm{I}_{\mathrm{up}}+\mathrm{I}_{\text {down }}\right)$ (see Fig. 1d), according to the expression (1):

$S=\frac{I_{\text {up }}-I_{\text {down }}}{I_{\text {up }}+I_{\text {down }}} \alpha \cos (\Delta \varphi(t))$

We have calibrated previously the BiMW detection limit for changes in the bulk refractive index obtaining a value of $2.5 \times 10^{-7}$ RIU (Refractive Index Units) corresponding to a minimum change of $\mathrm{N}_{\text {eff }}$ of $2.1 \times 10^{-8}$ which position the BiMW transducer as one of the most sensitive label-free optical sensors (Zinoviev et al. 2011). 
a)

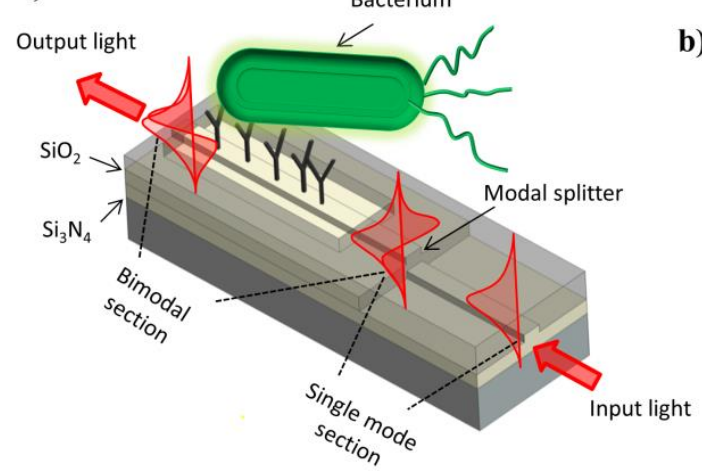

c)

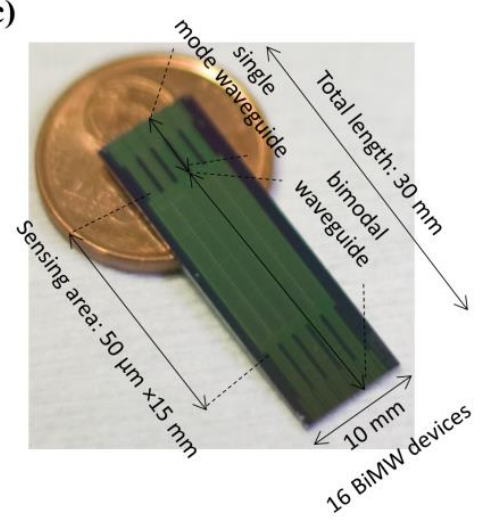

b)

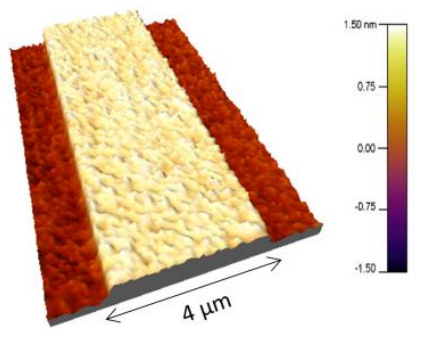

d)

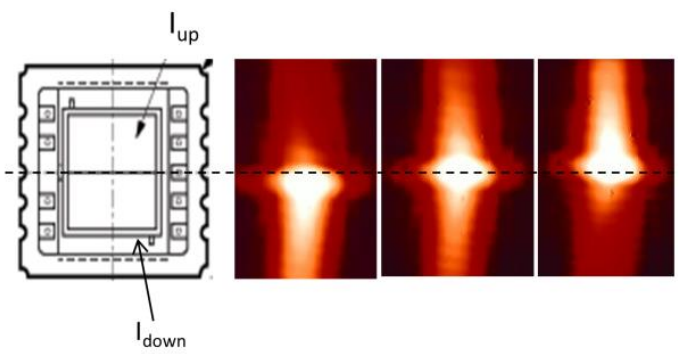

Fig. 1 (a) Sensing principle of a bimodal waveguide biosensor, the electromagnetic field associated with the light beam propagates through the waveguide, (b) AFM image of a rib waveguide of $1.5 \mathrm{~nm}$ height, (c) photo of a chip containing 16 BiMW interferometers and (d) processing of the signal, output light is distributed among up and down sections of the two-section photodetector.

To evaluate the potential of the BiMW biosensor for rapid and early detection of bacterial infections in ascitic liquid, we developed an immunoassay in which specific antibodies were immobilized on the sensor area of the device. The first step in this work was the initial evaluation of the biosensor sensitivity for microorganisms by the detection of the non-pathogen Bacillus cereus (B. cereus) in buffer medium as a proofof-concept. The second step was to check if the sample manipulation influenced in the bacteria breaking. We also investigated if the breaking of the bacteria could enhance the sensitivity of the biosensor; samples were mechanically broken and the detection was compared with the one from unbroken bacteria. The last step was the evaluation of the BiMW biosensor for bacterial detection in pure ascitic fluids. For this, we employed Escherichia coli (E. coli) in real ascites samples, as this is of the most common bacteria 
related to ascitic infections. To our knowledge, this is the first label-free biosensor for bacterial detection operating in real ascitic fluids.

\section{Materials and methods}

\section{Materials}

Lyophilized bacterial pellets of E. coli (ATCC 8739) and B. cereus (ATCC11778) were provided by ielab (Spain). Polyclonal antibodies were purchased from abcam ${ }^{\circledR}$ (Spain). Solvents for the device cleaning process: dry toluene, acetone, ethanol, hydrochloric acid $(\mathrm{HCl}, 35-38 \%)$, and methanol $(\mathrm{MeOH})$ were supplied by Panreac (Spain). Carboxyethysilanetriol sodium salt (CTES) was purchased from ABCR (Germany). (3Aminopropyl)triethoxysilane (APTES), p-phenylenediisothiocynate (PDITC), N,NDimethylformamide (DMF), pyridine, 1-ethyl-3(3-dimethylaminopropyl) carbodiimide hydrochloride (EDC), N-hydroxysuccinimide (NHS) and the components for phosphate buffer saline tween (PBST; $10 \mathrm{mM}$ phosphate, $2.9 \mathrm{mM} \mathrm{KCl}, 137 \mathrm{mM} \mathrm{NaCl}, 0.005 \%$ tween-20, pH 7.4), 2-N-morpholino ethanesulfonic acid (0.1 M MES, 0.5 M NaCl, pH 5.5-6), 4-(2-hydroxyethyl)-1-piperazineethanesulfonic acid (10 mM HEPES pH 7.4) and carbonate buffer $\left(0.1 \mathrm{M} \mathrm{Na}_{2} \mathrm{CO}_{3}, \mathrm{pH}\right.$ 9) were purchased from Sigma-Aldrich

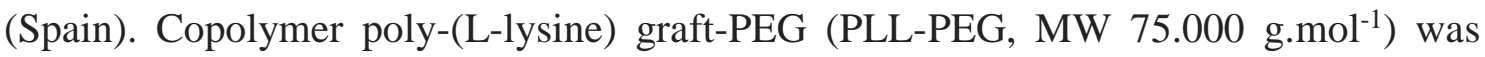
purchased from SuSoS (Switzerland), nylon membrane filter was purchase from VWR international (USA) and Polydimethylsiloxane (PDMS) was purchased from Sylgard ${ }^{\circledR}$ (USA). Milli-Q water from Millipore (USA) was always employed.

\section{Bacteria purification}

The bacterial pellets were reconstituted in water employing the volume indicated by the manufacturer. Therefore, the concentration of the stock solutions was $7.41 \times 10^{5} \mathrm{cfu} \cdot \mathrm{mL}^{-1}$ for $B$. cereus and $4.31 \times 10^{4} \mathrm{cfu} \cdot \mathrm{mL}^{-1}$ for $E$. coli. It is relevant to note that the values for bacteria concentration were certificated by different accredited laboratories conforming to internationally recognized standards. The bacterial solutions were aliquoted and stored at $-20{ }^{\circ} \mathrm{C}$ until use. Purification of bacteria was carried out by centrifugation at $3000 \mathrm{rpm}$ for $15 \mathrm{~min}$ at $4^{\circ} \mathrm{C}$. The supernatant was removed and the pellet was suspended in PBST for B. cereus and in ascitic fluid for E. coli. Each bacterial suspension was then mixed thoroughly using a pipette. Different concentrations of bacteria were prepared by diluting the stock solutions with the appropriate medium. For 
B. cereus, one $\mathrm{mL}$ of the stock solution was filtered with $0.2 \mu$ m nylon membrane filter. The filtered buffer was evaluated employing a nanophotometer from bioNovacientífica, s.l. (Spain) at $280 \mathrm{~nm}$.

\section{Ascitic fluid samples}

The ascitic fluid sample from the therapeutic paracentesis of a cirrhotic patient was provided and characterized by the Medicine Liver Unit, Hospital Vall d'Hebron (Barcelona, Spain). The ascitic fluid employed in this work contained a protein concentration of $1.9 \mathrm{~g} \cdot \mathrm{dL}^{-1}, 135 \mathrm{UI} \cdot \mathrm{L}^{-1}$ concentration of lactate dehydrogenase, $0.13 \times$ $10^{9}$ cells $\cdot \mathrm{L}^{-1}$ of total cells and $1 \times 10^{6}$ cells $\cdot \mathrm{L}^{-1}$ of red blood cells. The microbiological culture was negative. Sample was obtained after the patient had provided his/her informed consent and with the approval of the relevant Ethics Committee.

\section{Lysis of bacteria}

Different concentrations of bacterial solutions were lysed by thermal treatment (15 min at $100^{\circ} \mathrm{C}$ ) and 50 min of sonication with an ultrasonic bath FB15054 (Fisher Scientific, Spain). Optical density of the solutions was measured using the nanophotometer at 600 $\mathrm{nm}$ before and after the lysis treatment.

\section{Surface functionalisation and immobilisation of antibodies}

The chips were cleaned with acetone, ethanol and water, followed by sonication in methanol/hydrochloric acid 1:1 for $10 \mathrm{~min}$, rinsing with water and drying with a stream of nitrogen. The oxidation was carried out using $\mathrm{UV} / \mathrm{O}_{3}$ cleaner (BioForce Nanosciences, USA) for $1 \mathrm{~h}$. Then the chips were immersed in a $10 \% \mathrm{HNO}_{3}$ solution at $75^{\circ} \mathrm{C}$. Here, different functionalisations were carried out depending on the sample matrix:

Detection of B. cereus in buffer medium (CTES functionalisation): The chip was functionalizated with CTES silane, following the protocol detailed by GonzálezGuerrero et al. (González-Guerrero et al. 2013). The silane coated chip was placed on the experimental set-up and the next steps were done in-situ employing water as running buffer at a flow rate of $20 \mu \mathrm{L} \cdot \mathrm{min}^{-1}$. The carboxylic groups on the sensor surface were activated by injecting a solution of $0.2 \mathrm{M}$ EDC/0.05 M NHS in MES buffer. A polyclonal anti-B.Cereus/subtilis antibody solution in $10 \mathrm{mM}$ PBST at a concentration 
of $50 \mu \mathrm{g} \cdot \mathrm{mL}^{-1}$ was immediately injected over the freshly activated surface. Finally, the surface was blocked using PLL-PEG at a concentration of $0.5 \mathrm{mg} \cdot \mathrm{mL}^{-1}$ in HEPES buffer to avoid non-specific adsorptions.

Detection of E. coli in ascitic fluid (APTES functionalisation): The chip was incubated with $1 \%$ APTES silane solution in ethanol for $1 \mathrm{~h}$. It was then rinsed with ethanol and dried with a nitrogen stream. The chip was cured in an oven for $1 \mathrm{~h}$ at $110^{\circ} \mathrm{C}$ and activated with PDITC $20 \mathrm{mM}$ in 10\% of pyridine and DMF in dark for two hours. After incubation, the chip was washed with DMF and ethanol and dried with nitrogen. To incorporate the antibody, the sensor chip was immersed in a $50 \mu \mathrm{g} \cdot \mathrm{mL}^{-1}$ of anti-E.coli solution in carbonate buffer and allowed to react overnight in the dark and at room temperature. The chip was then washed with PBST and water, dried with nitrogen and placed on the set-up. PBST was employed as running buffer at a constant flow rate of $20 \mu \mathrm{L} \cdot \mathrm{min}^{-1}$ and the surface was blocked by injecting PLL-PEG at $0.5 \mathrm{mg} \cdot \mathrm{mL}^{-1}$ in HEPES buffer.

\section{Optical bimodal waveguide sensor and experimental set-up}

Bimodal waveguide devices were designed and fabricated as previously described (Zinoviev et al. 2011). For optical evaluation, a He/Ne laser $(\lambda=632.8 \mathrm{~nm})$ on TE polarization was used as a light source. Light was coupled into the waveguide using a 40x microscope objective. For sensing, a 4-channel flow cell was fabricated using PDMS with an internal channel volume of $15 \mu \mathrm{l}$; each channel was $1 \mathrm{~mm}$ wide and 500 $\mu \mathrm{m}$ high and covered four BiMW sensors. The solutions were flowed using a syringe pump and a circulation loop of $250 \mu \mathrm{L}$ and a flow rate of between $5-40 \mu \mathrm{L} \cdot \mathrm{min}^{-1}$. The intrinsic sensitivity of the BiMW device to the temperature changes was compensated by incorporating a temperature controller providing a temperature stabilization of the chip with an accuracy of 0.01 degrees. Data acquisition and analysis was performed using LabVIEW (National Instruments, USA) software.

\section{Immunoassay}

During all the measurements, PBST was flowed over the sensor surface at a constant flow rate of $20 \mu \mathrm{L} \cdot \mathrm{min}^{-1}$ until a stable baseline was reached. Bacterial samples were introduced into a $250 \mu \mathrm{L}$ loop and flowed over the sensor surface from low to high 
concentrations. After each measurement, $\mathrm{HCl}(100 \mathrm{mM})$ was employed to break the bacteria-antibody interaction at $30 \mu \mathrm{L} \cdot \mathrm{min}^{-1}$ in order to reuse the biosensor.

For a clearer representation of the data, calibration curves are presented as phase variation vs. logarithmic value of bacteria concentration. Binding of bacteria to the antibodies immobilized on the sensor surface was performed in triplicate. The standard deviations from the mean value were calculated and the error bars estimated for each measurement. The theoretical limit of detection (LOD) was calculated from the linear regression of the linear part of the representation of phase variation vs bacteria concentration. LOD was established as the lowest bacterial concentration that could provide a phase variation signal at least three standard deviations greater than a signal from a negative control.

\section{Results and discussion}

\section{Detection of B. cereus in buffer}

The BiMW sensor was biofunctionalised employing the silane CTES, providing the surface with a stable layer of carboxylic groups (González-Guerrero et al. 2013). In this way, it was possible to biofunctionalise the sensors located in one of the channels of our 4-channel fluidic cell without altering the rest of the sensor devices. The remaining silanised sensors could be used later (even 1 month later) since they were located in independent fluidic channels. The silanised sensor chip was then placed on the experimental set-up where the activation of the carboxylic groups and subsequent amide biofunctionalisation were carried out in-flow as previously explained.

A non-pathogenic bacterium (B. cereus) was employed as a model system for the evaluation of the biosensor performance in buffer medium. B. cereus is a large $(1 \times 3-4$ $\mu \mathrm{m}$ ), gram-positive and rod-shape bacterium widely distributed in nature (Vilain et al. 2006). Suspensions of $B$. cereus ranging from 70 to $7 \times 10^{5} \mathrm{cfu} \cdot \mathrm{mL}^{-1}$ were prepared in triplicate in PBST and were sequentially flowed through the sensor. Fig. 2a shows the calibration curve corresponding to triplicate measurements for each logarithmic concentration. The lowest concentration of $B$. cereus detected was $70 \mathrm{cfu} \cdot \mathrm{mL}^{-1}$ which produced a phase variation of $0.031 \times 2 \pi \mathrm{rad}$. The highest concentration detected was 7 $\times 10^{5} \mathrm{cfu} \cdot \mathrm{mL}^{-1}$ obtaining a phase variation of $1.13 \times 2 \pi \mathrm{rad}$. The specificity of the 
detection was evaluated by flowing a non-specific bacterium (E. Coli) at concentrations of $1 \times 10^{3}$ and $1 \times 10^{4} \mathrm{cfu} \cdot \mathrm{mL}^{-1}$. No significant binding was observed for any concentration, confirming that the signal contribution had come only from specific detection of $B$. cereus bacteria. The theoretical LOD for B. cereus detection was calculated from the linear fitting of the representation of the phase variation vs. bacteria concentration (inset of Fig. 2a) obtaining a value of $12 \mathrm{cfu} \cdot \mathrm{mL}^{-1}$.

The pretreatment employed for purification of bacteria (ultracentrifugation and mixing process) could have broken the bacteria and liberated antigens from the bacteria membrane that would have erroneously enhance the sensor signal. In order to check the contribution of this effect, different $B$. Cereus concentrations ranging from 70 to $7 \times 10^{5}$ $\mathrm{cfu} \cdot \mathrm{mL}^{-1}$ were filtered and each filtered buffer was sequentially injected into the sensor. In Fig. 2a, it can be observed that the filtered bacterial solutions gave a negligible signal. The results were confirmed by the nanophotometer (operating at $280 \mathrm{~nm}$ ) in which absorbance of these solutions was negligible indicating that the buffer was free of proteins. These experiments validated our procedure for sample preparation, ensuring that we have only entire bacteria after the purification process.

Representative signals of specific $B$. cereus detection $\left(7 \times 10^{3} \mathrm{cfu} \cdot \mathrm{mL}^{-1}\right)$, non-specific $E$. coli $\left(1 \times 10^{4} \mathrm{cfu} \cdot \mathrm{mL}^{-1}\right)$ and filtered buffer of a B. cereus solution $\left(7 \times 10^{3} \mathrm{cfu} \cdot \mathrm{mL}^{-1}\right)$ are shown in Fig. $2 b$. These signals show a phase variation of $0.27 \times 2 \pi$ rad for the detection of $7 \times 10^{3} \mathrm{cfu} \cdot \mathrm{mL}^{-1}$ of $B$. cereus and a negligible phase variation for the detection of $1 \times 10^{4} \mathrm{cfu} \cdot \mathrm{mL}^{-1}$ of $E$. coli, which indicated the specificity of the immunoassay.
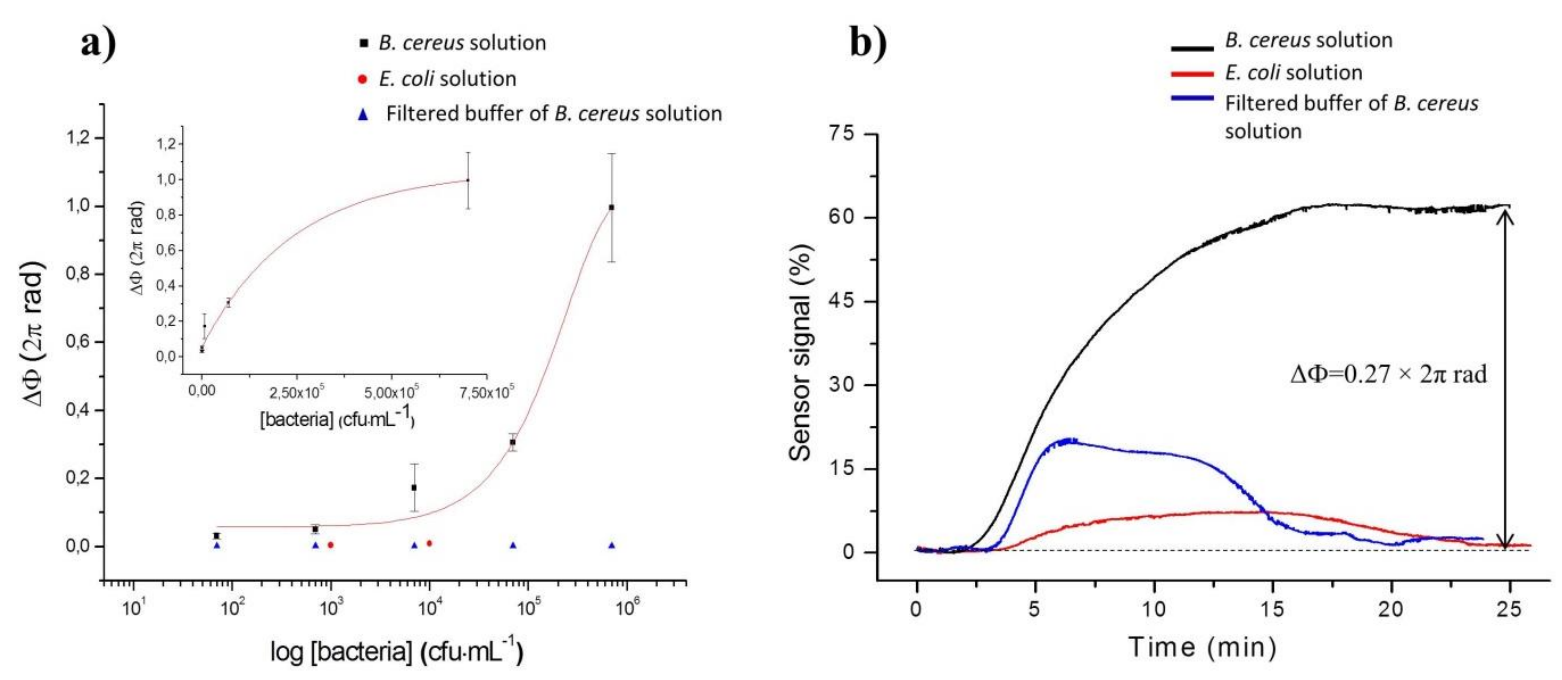
Fig. 2 (a) Calibration curve for the detection of triplicate logarithmic concentrations of B. cereus bacteria (black, squares) ranging from 70 to $7 \times 10^{5} \mathrm{cfu} \cdot \mathrm{mL}^{-1}$ [the exponential fit equation is given by $y=1.05-$ $\left.0.99 \cdot e^{\left(-4.13 \times 10^{\wedge}-6 x\right)}\right]$ in comparison with non-specific bacteria E. Coli (red, circles) at concentrations of $1 \times 10^{3} \mathrm{cfu} \cdot \mathrm{mL}^{-1}$ and $1 \times 10^{4} \mathrm{cfu} \cdot \mathrm{mL}^{-1}$ and concentrations of filtered buffer from $B$. Cereus solutions (blue, triangles) ranging from 70 to $7 \times 10^{5} \mathrm{cfu} \cdot \mathrm{mL}^{-1}$. In the inset: linear representation of the data for the $B$. Cereus detection [linear regression of the linear part is given by $y=2.18 \cdot 10^{-5} x+0.031, \mathrm{r}^{2}=0.94521$ ] and (b) real-time detection of specific B. cereus solution at a concentration of $7 \times 10^{3} \mathrm{cfu} \cdot \mathrm{mL}^{-1}$ (black line), non-specific $E$. coli solution at a concentration of $1 \times 10^{4} \mathrm{cfu} \cdot \mathrm{mL}^{-1}$ (red line) and filtered buffer from $B$. cereus solution at a concentration of $7 \times 10^{3} \mathrm{cfu} \cdot \mathrm{mL}^{-1}$ (blue line) by a direct immunoassay in PBST buffer.

Regeneration cycles (i.e. removal with acid conditions) are commonly employed to reuse the sensor surface in case this might be necessary, either to lengthen the surface life-time, to save costs or to study the reproducibility and optimization of the immunoassay protocols. In our study, after trying different regeneration solutions, the complete removal of the target bacteria was achieved by flowing $\mathrm{HCl} 100 \mathrm{mM}$ without altering the amount of antibody on the surface. As can be seen in Fig. 3a, after a regeneration step, the baseline for $B$. cereus, which had been previously detected at a concentration of $7 \times 10^{4} \mathrm{cfu} \cdot \mathrm{mL}^{-1}$, was recovered. Under these conditions, stability of the bioreceptor layer was maintained up to 6 cycles due to the limited stability of antibodies after aggressive acid medium treatments. Fig. 3b shows the triplicate measurements for the concentrations of $7 \times 10^{2}$ and $7 \times 10^{3} \mathrm{cfu} \cdot \mathrm{mL}^{-1}$ of $B$. cereus.

a)

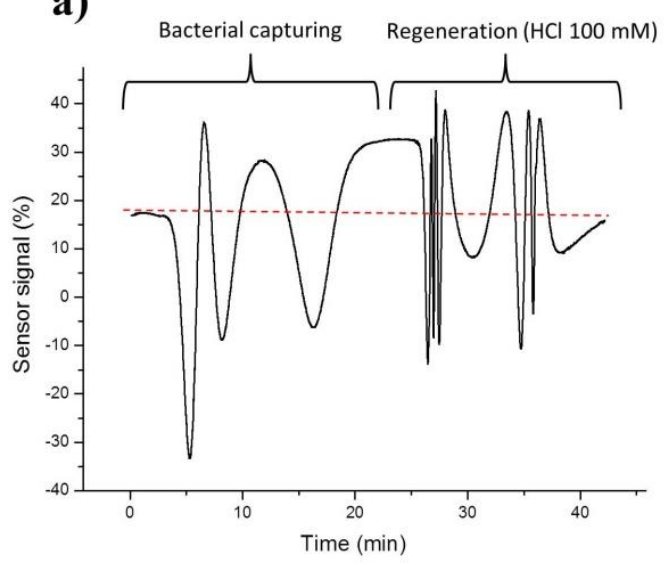

b)

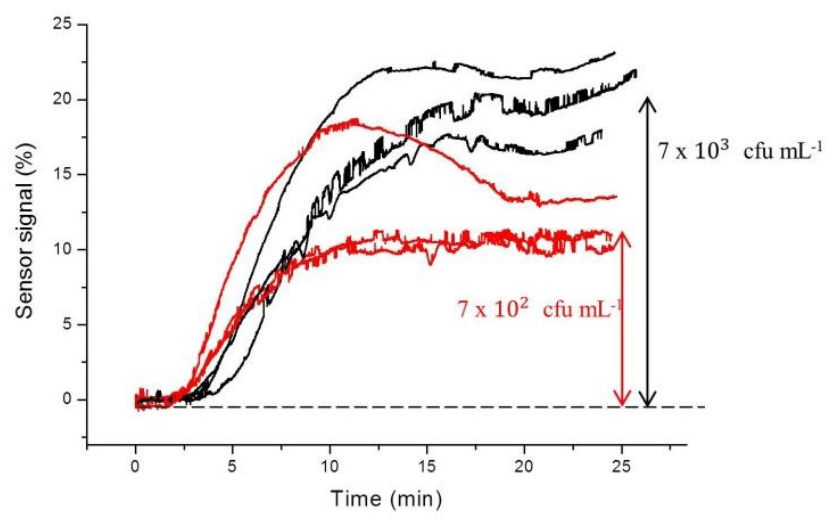

Fig. 3 (a) Real-time evaluation of a concentration of $7 \times 10^{4} \mathrm{cfu} \cdot \mathrm{mL}^{-1}$ of $B$. cereus, followed by regeneration using $\mathrm{HCl} 100 \mathrm{mM}$. The dash lines indicate the recovering of the baseline after the regeneration and (b) real-time triplicate measurements of $7 \times 10^{2}$ and $7 \times 10^{3} \mathrm{cfu} \cdot \mathrm{mL}^{-1}$ of B. cereus. 
As explained above, the fragmentation of the bacteria can enhance the signal for a determined concentration since dispersion of the bacterial membrane along the medium increases the probability of capturing the antigen targets. We investigated the increase of the sensitivity when bacterial samples were mechanically lysed before injecting in the biosensor. The lysis of the bacteria was confirmed by evaluating the optical density of the bacterial solutions. The value obtained for non-treated samples at a concentration of $7 \times 10^{5} \mathrm{cfu} \cdot \mathrm{mL}^{-1}$ was 0.704 , whereas for a lysed bacterial sample of the same concentration the value was 0.221 , indicating that the major part of the bacteria in the sample was fragmented. The calibration curve for logarithmic concentrations of lysed bacteria in comparison to the one for whole bacteria is shown in Fig. 4a. It can be calculated that the sensitivity (in terms of discrimination between different concentrations) is $6 \%$ higher for lysed bacteria than for whole bacteria. Fig. $4 \mathrm{~b}$, shows a comparison of real-time signals for the concentrations of $7 \times 10^{2}$ and $7 \times 10^{3} \mathrm{cfu} \cdot \mathrm{mL}^{-1}$ for lysed and whole bacteria. The increase in the signal due to the lysis pretreatment was around $35 \%$ and $30 \%$ for $7 \times 10^{2}$ and $7 \times 10^{3} \mathrm{cfu} \cdot \mathrm{mL}^{-1}$, respectively. It is worth mentioning that the sonication treatment is time-consuming, thus the advantages in the increase of the signal must be significant (more than 100\%) in order to consider its implementation in this type of analysis. From these findings, it can be concluded that the increase of the signals obtained by sonicating the samples did not justify the incorporation of a pretreatment step which could have delayed the result of the analysis by more than one hour.
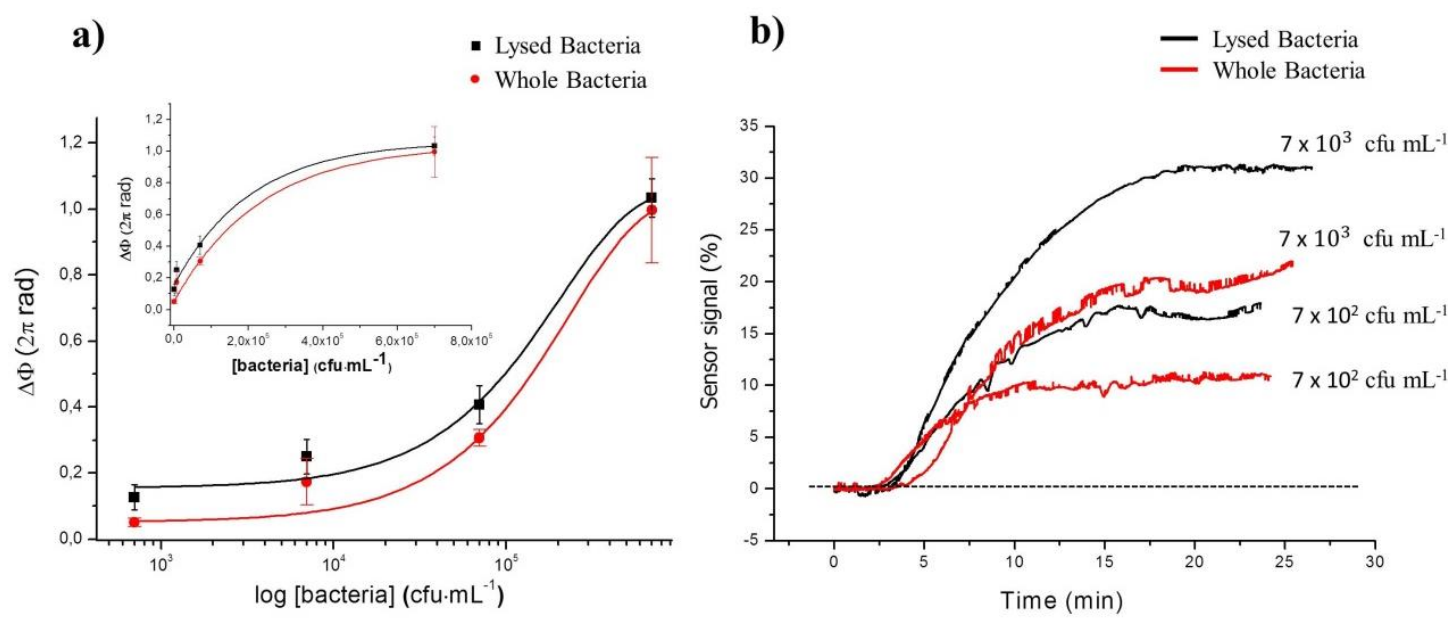

Fig. 4 (a) Calibration curves for the logarithmic concentration of lysed B. cereus solutions ranging from $7 \times 10^{2}$ to $7 \times 10^{5} \mathrm{cfu} \cdot \mathrm{mL}^{-1}$ in PBST buffer [the exponential fit equation is given by $y=1.06-0.90 \cdot e^{\left(-4.8 \times 10^{\wedge-6}\right.}$ ${ }^{x}$ ] in comparison with the same concentration solutions of whole bacteria [the exponential fit equation is 
given by $y=1.0-0.99 \cdot e^{\left(-4.3 \times 10^{\wedge}-6 x\right)}$. In the inset: linear representation of the data for lysed B. Cereus detection [linear regression of the linear part is given by $y=3.8 \cdot 10^{-6} x+0.15, \mathrm{r}^{2}=0.998$ ] and for whole B. Cereus detection [linear regression of the linear part is given by $y=3.6 \cdot 10^{-6} x+0.05, \mathrm{r}^{2}=0.953$ ] and (b) real-time signals for whole and lysed bacteria in buffer solution for $7 \times 10^{2}$ and $7 \times 10^{3} \mathrm{cfu} \cdot \mathrm{mL}^{-1}$.

\section{Detection of E. coli in ascitic fluid}

The following stage of this study concerned the direct and label-free bacterial detection in $100 \%$ human ascitic fluid using the BiMW biosensor. As previously described, this analysis can become especially complex due to interferences and undesired non-specific adsorption of matrix components present in the ascitic fluid. In the case of a label-free detection and, in particular, in evanescent wave-based biosensors, where signals are directly related with mass changes on the sensor surface, this must be fully minimized. As listed above, the ascitic fluid employed in this work contained concentrations of proteins in the same range $\left(20 \mathrm{mg} \cdot \mathrm{mL}^{-1}\right)$ as serum or plasma $\left(60-80 \mathrm{mg} \cdot \mathrm{mL}^{-1}\right)$. In addition, the high cell content of ascitic fluid $\left(1.3 \times 10^{5} \mathrm{cell} \cdot \mathrm{mL}^{-1}\right)$ represented another source of potential non-specific adsorptions. Therefore, it is clear that the detection of bacteria in undiluted ascitic fluid samples is a new and complex challenge for optical label-free immunosensors.

The method employed to functionalise the surface must assure a good coverage and non-fouling properties. We employed an APTES functionalisation for immobilizing the bioreceptors in the case of detection in ascitic fluid since previous experiments (not shown) demonstrated better non-fouling properties for complex matrixes than the CTES silanisation. This effect has been mainly attributed to the formation of compact monolayers by $\pi-\pi$ stacking of the PDITC linker (Gandhiraman et al. 2010). Additionally, we employed a solution of PLL-PEG to block the sensor surface before the immunoassay. This methodology for reducing non-specific binding when evaluating real samples has been previously optimised and validated (Soler et al. 2014).

For the detection of bacterial infections in ascitic fluid, we selected E. coli since it is highly common in SBP and it is related to nosocomial infections in hospitals. E. coli has a size of $2 \mu \mathrm{m}$ in length and $0.5-1 \mu \mathrm{m}$ in width and it is a gram-negative, facultative anaerobic and rod-shaped bacterium. To detect E. coli using the BiMW biosensor, solutions ranging from $40 \mathrm{cfu} \cdot \mathrm{mL}^{-1}$ to $4 \times 10^{4} \mathrm{cfu} \cdot \mathrm{mL}^{-1}$ were prepared in triplicate by 
spiking the ascitic fluid with different amounts of the stock solution. PBST was employed as running buffer and different concentrations of spiked ascitic fluid were flowed through the channel of the biosensor. The sensor surface was then regenerated by injecting $\mathrm{HCl} 100 \mathrm{mM}$. Assays with PBST as running buffer resulted in good repeatability until the seventh cycle.

The calibration curve for triplicate measurements of each logarithmic concentration is shown in Fig. 5. The phase variation for the highest concentration evaluated $\left(4 \times 10^{4}\right.$ $\left.\mathrm{cfu} \cdot \mathrm{mL}^{-1}\right)$ was $2.5 \times 2 \pi \mathrm{rad}$ and for the lowest concentration $\left(40 \mathrm{cfu} \cdot \mathrm{mL}^{-1}\right)$ was $0.21 \times 2 \pi$ rad. LOD calculated from the fitting of the linear representation of E. coli detection (in the inset) was $4 \mathrm{cfu} \cdot \mathrm{mL}^{-1}$. To evaluate the contribution of the sample matrix to the signal, pure ascitic fluid was injected into the biosensor. Injection of undiluted ascitic fluid in triplicate resulted in small and constant background signals due to the matrix $(0.10,0.15$ and $0.13 \times 2 \pi \mathrm{rad})$. After each evaluation of the ascitic fluid non-specific adsorption, bioreceptor surface was cleaned by injecting the regeneration solution before a new injection. Fig. 5, shows the specific calibration curve compared to the average of the phase variation $(0.13 \pm 0.02 \times 2 \pi \mathrm{rad})$ obtained for the pure ascitic fluid detection. As can be observed, the signal due to the non-specific adsorption of the ascitic fluid matrix was negligible when comparing with the specific E. coli signal.

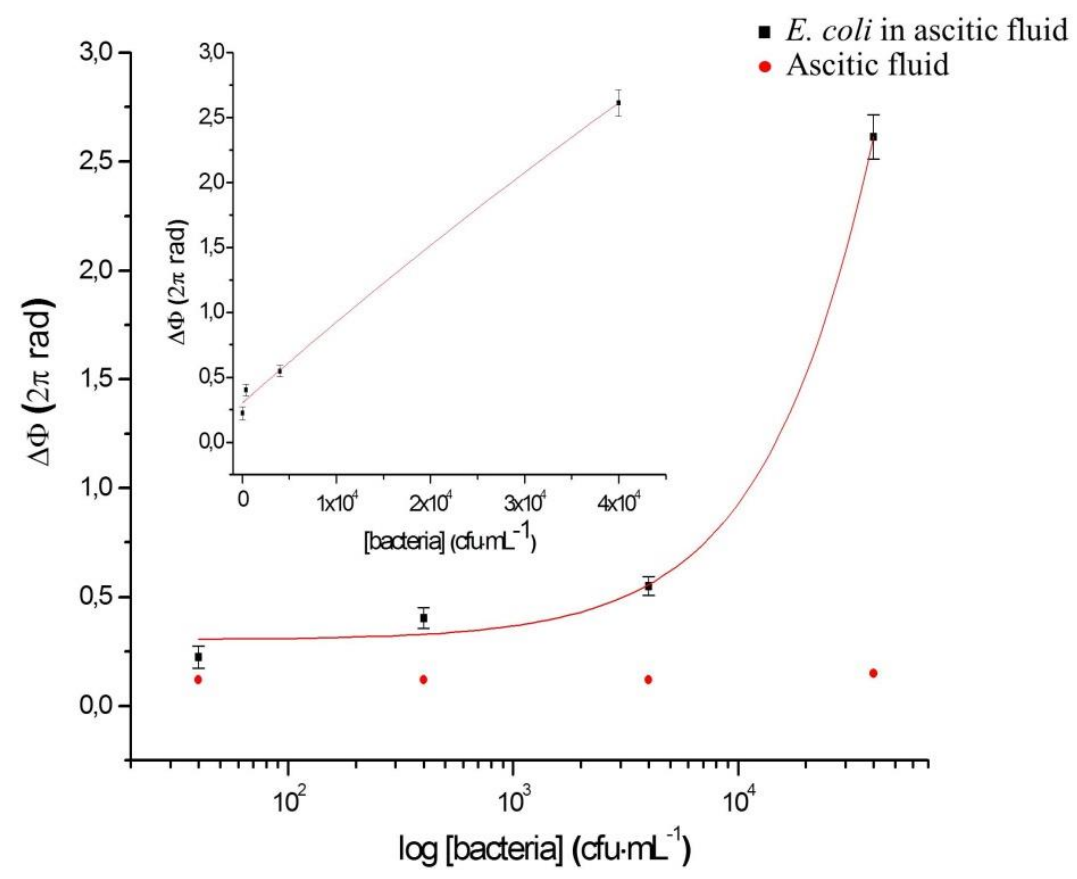


Fig. 5 Calibration curve for triplicate spiked concentrations of E. coli ranging from 40 and $4 \times 10^{4} \mathrm{cfu} \cdot \mathrm{mL}^{-}$ 1 in ascitic fluid (black, squares) [the exponential fit equation is given by $y=12.5-12.2 \cdot e^{\left(-5.3 \times 10^{\wedge}-6 x\right)}$ ] and unspecific detection of pure ascitic fluid. In the inset: linear representation of the data for E. Coli detection [the linear regression is given by $y=5.7 \cdot 10^{-5} x+0.3, \mathrm{r}^{2}=0.982$ ].

Fig. 6a shows a representative real-time signal for the detection of a spiked concentration of $E$. coli of $4 \times 10^{3} \mathrm{cfu} \cdot \mathrm{mL}^{-1}$ in human ascitic fluid. The real-time measurement of pure ascitic fluid is shown in Fig. 6b. An increase of the resulting phase variation for the E. coli spiked sample can be observed, indicating specific detection of the bacteria.

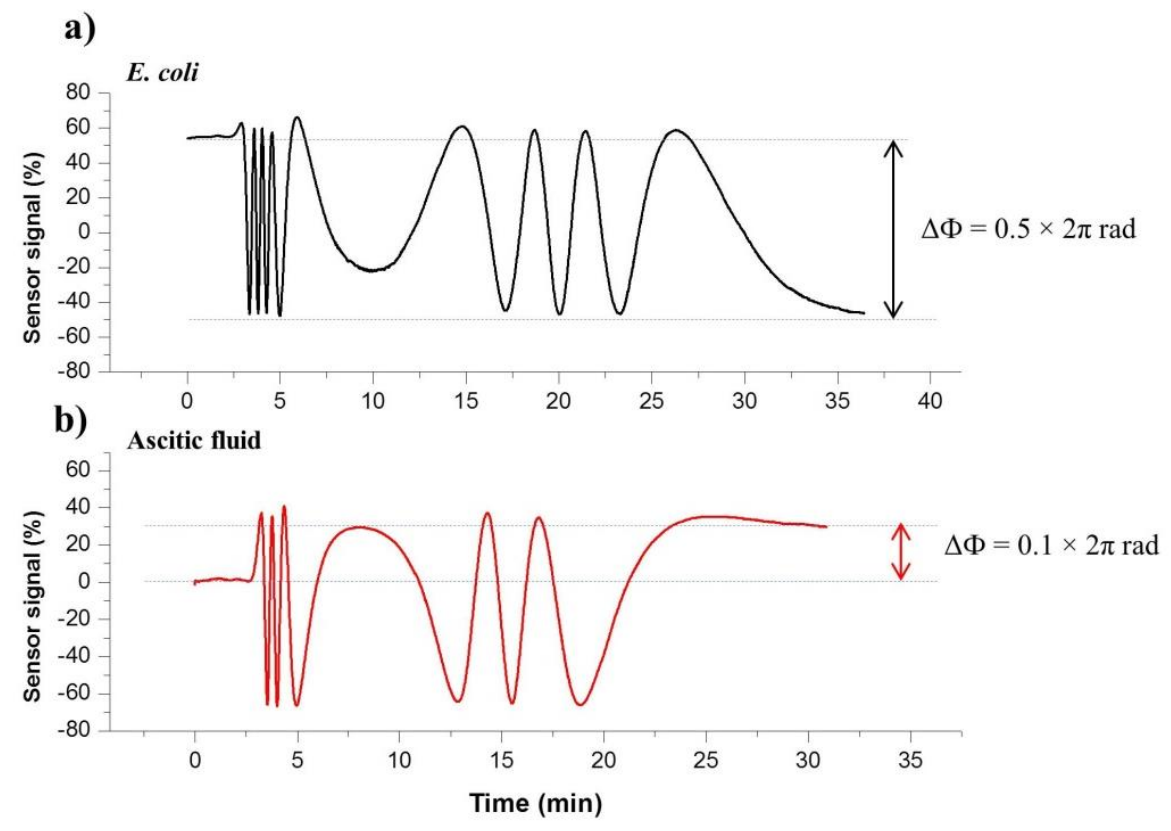

Fig. 6 Real-time measurements of ascitic fluid (a) spiked with E. coli at a concentration of $4 \times 10^{3} \mathrm{cfu} \cdot \mathrm{mL}^{-}$ ${ }^{1}$ and (b) pure ascitic fluid.

In this work we have demonstrated that the BiMW biosensor can detect extremely low bacterial concentration in a label-free and fast way. The superior sensitivity of the BiMW device when comparing with other label-free biosensors can be attributed to the large effective sensing area $(15000 \mu \mathrm{m}$ long) which increases the probabilities to bind the microorganisms. It must be highlighted that, despite the high content of proteins and cells in the ascitic fluid, exceptional LOD was obtained for the detection of harmful bacteria which indicates, not only a highly sensitive transducer but an intensive effort in developing the appropriate biofunctionalization technique for each particular application. 


\section{Conclusions}

We present here the development of a BiMW biosensor for rapid and label-free detection of spontaneous bacterial peritonitis. Our results show that the BiMW biosensor was capable of detecting $E$. coli at a concentration as low as $40 \mathrm{cfu} \cdot \mathrm{mL}^{-1}$ employing a label-free direct immunoassay in real ascitic fluid obtaining a LOD of 4 $\mathrm{cfu} \cdot \mathrm{mL}^{-1}$. Furthermore, each detection was performed in 15 minutes, without the need of any purification pretreatment or specially trained personnel.

It must be noted that the investigation of the cross-reactivity of the antibodies employed for $E$. coli with other common bacteria in SBP was not the aim of the present work. However, the study of the employed antibodies and their unspecific interactions with other bacteria present in human ascetic fluid is the next step in the development of the presented biosensor. The variability in the content and composition (salt, $\mathrm{pH}$ and cells) of ascitic liquid from different patients could affect the result of the immunoassay indicating the need for future studies on how variations in ascitic liquids from different patients influence bacterial immunodetection. Finally, despite the detection of very low bacterial concentrations is not a requirement for the selected bioapplication, it is clear that a proper microfluidic design is a key factor to enhance the probability of microorganism binding to the biofunctionalised sensor surface and work is in progress to incorporate a more advanced microfluidic cell.

As conclusion, the results presented in this work show the great potential of the BiMW technology for the label-free and cost-effective identification of the most frequent bacteria present in ascitic fluid. Moreover, this technology could be easily used in clinical settings to facilitate early bacterial diagnostics thereby improving patient prognosis and reducing the costs associated with medical complications in hospitalized patients.

\section{Acknowledgements}

J. Maldonado acknowledges the Mexican National Council for Science and Technology (CONACYT). The authors acknowledge the financial support from Project EPISENS of Spanish Ministry of Science and Innovation (TEC2012-34280) and HEPATOPOC project from CIBER-BBN. We acknowledge Dr. Macarena Talero and Dr. Victor Vargas from Vall D’Hebrón Hospital (Barcelona) for the supply of ascitic fluid. The 
nanoB2A is a consolidated research group (Grup de Recerca) of the Generalitat de Catalunya and has support from the Departament d'Universitats, Recerca i Societat de la Informació de la Generalitat de Catalunya (2014 SGR 624). ICN2 is the recipient of Grant SEV-2013-0295 from the "Severo Ochoa Centers of Excellence" Program of Spanish MINECO.

\section{References}


Acharya, G., Chang, C.-L., Savran, C., 2006. An Optical Biosensor for Rapid and Label-Free Detection of Cells. Journal of the American Chemical Society 128(12), 3862-3863.

Arya, S.K., Singh, A., Naidoo, R., Wu, P., McDermott, M.T., Evoy, S., 2011.

Chemically immobilized T4-bacteriophage for specific Escherichia coli detection using surface plasmon resonance. Analyst 136(3), 486-492.

Balasubramanian, S., Sorokulova, I.B., Vodyanoy, V.J., Simonian, A.L., 2007. Lytic phage as a specific and selective probe for detection of Staphylococcus aureus--A surface plasmon resonance spectroscopic study. Biosensors \& bioelectronics 22(6), 948955.

Fernández, J., Gustot, T., 2012. Management of bacterial infections in cirrhosis. J Hepatol 56, Supplement 1(0), S1-S12.

Gandhiraman, R.P., Gubala, V., Le, N.C., Volcke, C., Doyle, C., James, B., Daniels, S., Williams, D.E., 2010. Deposition of chemically reactive and repellent sites on biosensor chips for reduced non-specific binding. Colloids and surfaces. B, Biointerfaces 79(1), 270-275.

González-Guerrero, A.B., Alvarez, M., Castaño, A.G., Domínguez, C., Lechuga, L.M., 2013. A comparative study of in-flow and micro-patterning biofunctionalization protocols for nanophotonic silicon-based biosensors. Journal of Colloid and Interface Science 393(0), 402-410.

Maalouf, R., Fournier-Wirth, C., Coste, J., Chebib, H., Saïkali, Y., Vittori, O., Errachid, A., Cloarec, J.-P., Martelet, C., Jaffrezic-Renault, N., 2007. Label-Free Detection of Bacteria by Electrochemical Impedance Spectroscopy: Comparison to Surface Plasmon Resonance. Analytical Chemistry 79(13), 4879-4886.

McGovern, J.-P., Shih, W.Y., Rest, R., Purohit, M., Pandya, Y., Shih, W.-H., 2008. Label-free flow-enhanced specific detection ofBacillus anthracis using a piezoelectric microcantilever sensor. Analyst 133(5), 649-654.

Ohk, S.H., Bhunia, A.K., 2013. Multiplex fiber optic biosensor for detection of Listeria monocytogenes, Escherichia coli O157:H7 and Salmonella enterica from ready-to-eat meat samples. Food Microbiol 33(2), 166-171.

Salam, F., Uludag, Y., Tothill, I.E., 2013. Real-time and sensitive detection of Salmonella Typhimurium using an automated quartz crystal microbalance (QCM) instrument with nanoparticles amplification. Talanta 115, 761-767. 
Soler, M., Estevez, M.C., Alvarez, M., Otte, M.A., Sepulveda, B., Lechuga, L.M., 2014. Direct detection of protein biomarkers in human fluids using site-specific antibody immobilization strategies. Sensors (Basel, Switzerland) 14(2), 2239-2258.

Subramanian, A., Irudayaraj, J., Ryan, T., 2006. A mixed self-assembled monolayerbased surface plasmon immunosensor for detection of E. coli O157:H7. Biosensors and Bioelectronics 21(7), 998-1006.

Valadez, A., Lana, C., Tu, S.-I., Morgan, M., Bhunia, A., 2009. Evanescent Wave Fiber Optic Biosensor for Salmonella Detection in Food. Sensors 9(7), 5810-5824.

Vilain, S., Luo, Y., Hildreth, M.B., Brozel, V.S., 2006. Analysis of the life cycle of the soil saprophyte Bacillus cereus in liquid soil extract and in soil. Applied and environmental microbiology 72(7), 4970-4977.

Wang, Y., Knoll, W., Dostalek, J., 2012. Bacterial Pathogen Surface Plasmon Resonance Biosensor Advanced by Long Range Surface Plasmons and Magnetic Nanoparticle Assays. Analytical Chemistry 84(19), 8345-8350.

Zinoviev, K.E., Gonzalez-Guerrero, A.B., Dominguez, C., Lechuga, L.M., 2011. Integrated Bimodal Waveguide Interferometric Biosensor for Label-Free Analysis. Lightwave Technology, Journal of 29(13), 1926-1930.

Zourob, M., Mohr, S., Brown, B.J.T., Fielden, P.R., McDonnell, M.B., Goddard, N.J., 2005. Bacteria detection using disposable optical leaky waveguide sensors. Biosensors and Bioelectronics 21(2), 293-302. 